\title{
AN AGENT-BASED APPROACH TOWARDS THE DESIGN OF INDUSTRIAL HOLONIC CONTROL SYSTEMS
}

\author{
Boris Suessmann, Armando W. Colombo, Ralf Neubert \\ Schneider Electric, Automation Business, Development Central \\ Steinheimer Strasse 117, 63500 Seligenstadt, Germany \\ \{boris.suessmann, armando.colombo, ralf.neubert\}@modicon.com
}

\begin{abstract}
After the description of the underlying principles on which the "multiagentbased production control" technology and the "holonic manufacturing control" concept within the intelligent manufacturing system paradigm are based, this work proposes an approach that supports the design of agent-based manufacturing control systems for different industrial holonic manufacturing scenarios. The results of the application to a pilot cell at industrial level are very promissory, showing that the approach seems to be very suited in accommodating heterogeneous hardware and software components in both their manufacturing control and information system, and in integrating existing/legacy systems.
\end{abstract}

\section{INTRODUCTION}

On one side, the recent production technologies reflect a world-wide trend towards both, batches of small and medium size, and product families of increased variety. Customers are more and more asking for personalised products. This tendency often comes in conflict with the demand on high productivity, i.e. on productiontimes/time-to-market minimisation and on simultaneous improvement of machine utilisation. For example, today's mass production systems like transfer lines in automotive-industry are suffering of poor capacity utilisation. Although the utilisation of individual machines can be as high as $98 \%$, the overall utilisation of the factories is about 50 to $70 \%$. This is due to the fact that there is typically only one linear line of production. So if somewhere at the shop floor a bottleneck exists, and every system has a bottleneck, the whole production line is influenced.

On the other side, current industrial control at the physical machine level is typically implemented using large, and often expensive, hardware platforms that support monolithic computer control applications. As a result, when the control system is installed, commissioning can take months to complete, and once the system is operational, changes are often complex and difficult. All these factors contribute significantly to the total cost of the industrial control project and of course, of the final product. 
To redress this situation, new revolutionary manufacturing concepts and emerging manufacturing control technologies, which take advantage of the newest mechatronics, information and communication technologies and paradigms, are being researched and developed since the last decade of the $20^{\text {th }}$ century (Tzafetas, 1997).

One promising structure, in this respect, is to have a conglomerate of distributed, autonomous, intelligent, fault-tolerant, and reusable manufacturing units, which operates as a set of co-operating entities. Each entity is capable to dynamically interact with each other to achieve both local and global manufacturing objectives, from the physical/machine control level on the shop floor to the higher levels of the factory management systems. This new generation of manufacturing systems is referenced as Intelligent Manufacturing Systems (IMS).

On one hand, several emerging concepts that advocate such structure have been reported in the literature (Tharumarajah et al., 1996). Holonic manufacturing (see (Hayashi, 1993) and the references therein) is an example of the new manufacturing paradigms. On the other hand, agent-based software systems are becoming a key control software technology for production control systems (Jennings, Wooldridge, 1998), (Parunak et al., 1998), (Shen, Norrie, 1999), (Colombo et al., 2001).

According to the practical experiences of the authors when working with agentoriented production control technology in automotive-industry (Schoop et al., 2001), factors like the "time-to-market" can be decreased in a $10 \%$ order as a result of decreasing "start-up-time" and increasing "robustness" and "agility" of the system. Moreover, production systems that were developed for mass-production are capable, when they are agent-based managed and controlled, to accept prototype- and customeroriented-production, without modifying their structure and without interrupting their normal production. An agent-controlled production system within a Holonic Manufacturing Systems framework provides rapid reactive and dynamic re-configurable manufacturing equipment to facilitate an agile, flexible and robust, management framework for the control over the system.

The so far available realisation experience and the scientific discoveries point out, that the further development requires a generic, systematic approach towards a common understanding of the technology versus the punctual developments of the past. The successful application of both, the "holonic manufacturing system" and the "agent-based manufacturing control system" technologies for making the Intelligent Manufacturing System at industrial level a reality necessitates new engineering methods, processes and tools. These must be on one hand as standardised as possible and on the other hand adapted to the conditions of the different production types and industrial scenarios.

In this paper the underlying principles on which the "physical agent" and "holonic" concepts are based are first described. After this description, the main specifications of an engineering methodology for the agentification of manufacturing systems, based on our last research results ((Colombo et al., 2001), (Schoop et al., 2001)), and in agreement with other studies ((Shen, Norrie, 1997), (Bohnenberger et al., 1998), (Parunak et al., 1998), (Bussmann, Schild, 2001), (Bussmann et al., 2001) and (Ritter et al., 2002)), are presented as a practical solution to the holonic manufacturing control paradigm.

This paper will show that this solution is compatible with other mechanisms and architectures for "Holonic Control" proposed recently, such as the "Holonic Control Device" presented in (Christensen, 2000) and/or "The Holonic Enterprise" proposed by M. Ulieru et al. in (http://www.fipa.org). The integration of our proposal and the above projects, although still in the early stages, is already in scope.

This paper is organised as follows: First, section 2 reviews the latest results in the field of agent-based industrial control design and presents issues relating to the synthesis of agent-based manufacturing control systems. Further this section shows a method of 
agentification. Section 3 details the main characteristics of the agentification method and a first analysis. Section 4 describes an extension to the existing method to remove the problems identified in section 0 . Finally, section 5 rounds up the paper with conclusions and an overview of planned further developments related to the approach presented here.

\section{AGENTIFICATION OF PRODUCTION SCENARIOS}

This section discusses the integration of structural, functional and manufacturing management and control knowledge in agent-based industrial control system design. After an overview of reported results in the field, issues relating to the synthesis of agent-based manufacturing control systems (i.e., agentification of manufacturing scenarios) are presented.

As any other design activity, the design of agent-based manufacturing control systems consists of the creation and manipulation of objects, which are called here "production agents".

Agent system theories have been developed to innovating a number of control applications that are highly influenced by the exploding possibilities of new ICTSystems. Today's most demanding operational areas for technical agents are:

- Telecommunications

- Data-mining

- Traffic control

- Distributed trade systems

- Management of huge heterogeneous information networks like the Internet Unfortunately neither these agent systems nor the underlying theory can be used to design production agents, i.e., agent-based production systems. The main reasons are:

- Production agents are distributed physical agents while most of the current technology is dealing with software agents.

- Agent-systems in production are inhomogeneous multi-agent-systems while the so far realized applications are either homogenous or single agent systems.

- Production agents require a dynamic and controllable decision core to enable agile manufacturing system adaptation and (re)-configuration and support decision rule development.

- Production agents are self-reconfiguring; intelligent distributed automation elements that have to operate in a stochastic environment where hard real-time constraints must be met to achieve reliable system operation, while the software multi-agentsystems developed so far do not consider time as a problem at all.

These characteristics describe the transition from software agent-systems to Holonic Manufacturing Control Systems.

In any application domain, knowledge can be split between structural knowledge (about the objects and physical entities), functional knowledge (about how the objects behave and interact). This was the basic rationale underlying the structure-function paradigm proposed in (Cornelio et al., 1990). However, whenever the knowledge is used in a dynamic way for design purposes, a large gap, both practical and conceptual, exists between the structure-function specification and an implementation satisfying that specification as a constraint. Functionality represents complex behaviour whose achievement implies the realisation of suitable production control strategies. Many different control organisations compatible with the same high-level structural and functional specifications can be developed (Caselli et al., 1992). 
These are the basic motivations leading to the proposal of an agent-based systemmodelling paradigm oriented to the intelligent manufacturing domain, where proper consideration is given to management and control in the early modelling stages. The result is an engineering method, which supports a design synthesis of agent-based intelligent manufacturing scenarios, where physical, functional; and management and control specifications are integrated into an object called "production agent".

In Figure 1 an example of a production agent is shown, together with a picture of a flexible production cell, located at Schneider Electric Automation Business in Germany, which serves as pilot application of the approach outlined in this paper.
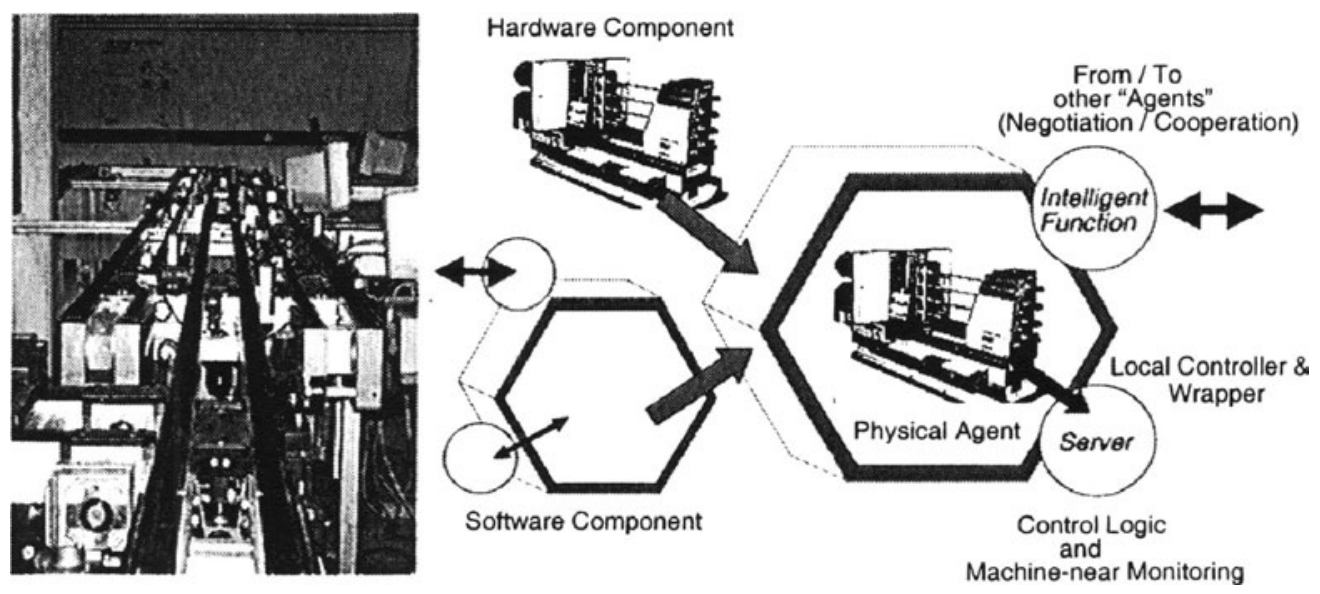

Figure 1 - Production agents and flexible production systems

In (Ritter et al., 2002), a method for identification of agents in a manufacturing system is described, which is mainly based on the following steps:

1. Identify all persistent manufacturing objects.

2. List all physical dependencies between the identified manufacturing objects.

3. List all logical dependencies between the identified manufacturing objects.

4. Aggregate all objects with physical dependencies into an object. (p-aggregation)

5. Aggregate all object with logical dependencies. (a-aggregation)

The resulting aggregates are the agents of the manufacturing system.

This method helps to find a suitable set of agents in the manufacturing system. As there are no dependencies between the agents, due to the method of aggregating object which depend on one another, there are also no deadlocks on the physical and logical level. We will call this method "IPA-method".

\section{CASE STUDY}

In the following is shown the application of the method proposed here, on a flexible manufacturing system. This case study is composed of both the pilot flexible production cell depicted in Figure 1 (layout in Figure 2), and an existing agent-based production system for cylinder head manufacturing referenced in (Colombo et al., 2001). The system produces the end products (cylinder head) from the raw material with CNC machines. The CNC machines are all capable to execute different machining operations. A dispatcher assigns orders to raw workpieces mounted on pallets. The orders may define different machining resulting in different end products. Shift-tables shift pallets 
between conveyors to route them to their next destination. An unloader finally detaches the processed workpieces from the pallets and puts them into a storage.

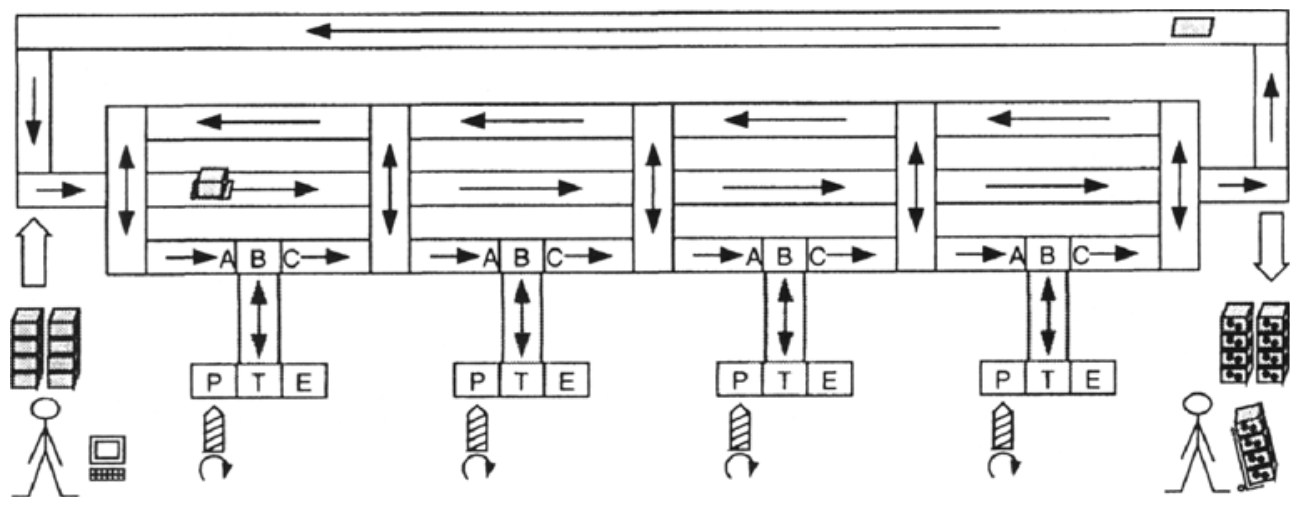

Figure 2 - Flexible manufacturing system

First, the manufacturing objects are identified ( Table 1).

Table 1 - Manufacturing objects

\begin{tabular}{|c|c|c|}
\hline Name & Symbol & Manufacturing function \\
\hline Raw storage & 国 & Stores raw workpieces \\
\hline Loader & & Loads pallets with raw workpieces \\
\hline Dispatcher & 交口 & Generates orders for pallets \\
\hline Conveyor belt & $\Longrightarrow$ & Transports pallets to shift-tables \\
\hline Shift-table & if & Shifts pallets between conveyors \\
\hline Loading conveyor & $\rightarrow A$ & Transports pallets to lifting place \\
\hline Lifting place & $\mathrm{B}$ & $\begin{array}{l}\text { Transports pallet to/from T-stem or passes } \\
\text { pallets by }\end{array}$ \\
\hline Unloading conveyor & $B \rightarrow$ & Transports pallets from lifting place \\
\hline T-stem & 团 & Transports pallets to temporary place \\
\hline Processing place & $P$ & Holds pallets for processing \\
\hline Temporary place & $\mathrm{TT}$ & $\begin{array}{l}\text { Moves pallets between T-stem, processing } \\
\text { place, and exchange place }\end{array}$ \\
\hline Exchange place & $E$ & Holds pallets during exchange \\
\hline CNC/Spindle & 寊 & Processes workpiece (drilling, milling,...) \\
\hline Unloader & & $\begin{array}{l}\text { Removes workpieces from pallets into exit } \\
\text { storage }\end{array}$ \\
\hline Exit storage & & Stores processed workpieces \\
\hline
\end{tabular}

Next, the dependencies between the manufacturing objects are listed ( Table 2). With these dependencies, the manufacturing objects are aggregated into agents. The main property of these agents is their independence from each other, by construction (see Figure 3). 
Table 2 - Dependencies between manufacturing objects

\begin{tabular}{|l|l|l|}
\hline Name & $\begin{array}{l}\text { Physical } \\
\text { dependency }\end{array}$ & Logical dependency \\
\hline Raw storage & Loader & \\
\hline Loader & Raw storage & Dispatcher \\
\hline Dispatcher & & \\
\hline Conveyor belt & & State of shift-table \\
\hline Shift-table & & \\
\hline Loading conveyor & & State of lifting place \\
\hline Lifting place & & \\
\hline Unloading conveyor & & State of lifting place \\
\hline T-stem & & State of lifting place, Temporary place \\
\hline Temporary place & & $\begin{array}{l}\text { State of T-stem, processing place, } \\
\text { exchange place }\end{array}$ \\
\hline Exchange place & & Temporary place \\
\hline Processing place & & Temporary place \\
\hline CNC/Spindle & & \\
\hline Unloader & & \\
\hline Exit storage & Unloader & \\
\hline
\end{tabular}

Note: In this example the method aggregates all transporting objects into one huge transport agent. This is intended by the method. Give the transport agent a transport order for a given pallet and it cares for the transport.

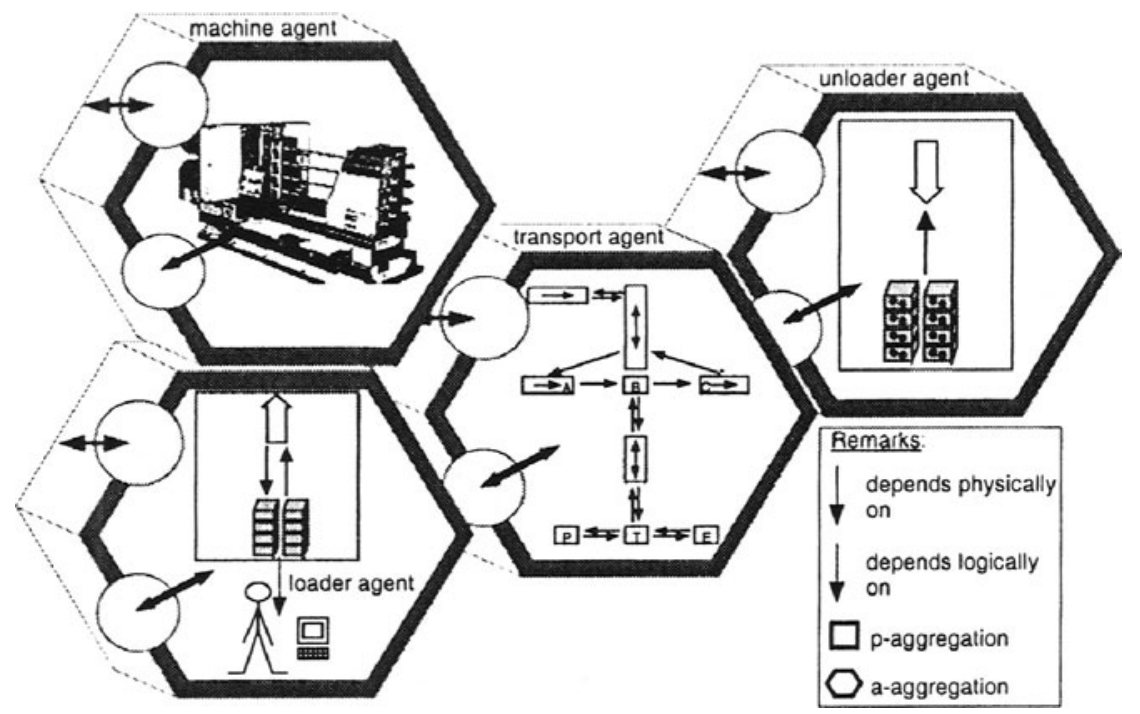

Figure 3 - Aggregation of manufacturing objects into agents

\subsection{Analysis of the Method}

The method identifies autonomous components. These components have to interact with each other to build the complete plant. The method does not handle the design of communication protocols for the identified agents. The result of the method is a flat agent community (Figure 4 (a)). 
As long as a physical or logical dependency is crossing physical boundaries, this flat agent community does not represent physical boundaries. This is an unwanted result, if you want to construct intelligent components for reuse. And it does not represent the reality, where you often have a hard unit of processing and loading and a soft unit of CNC- and PLC-programs. Another problem is the coarseness of the agent community. Flexible manufacturing systems depend on flexible transport systems. When there are dependencies between different modules of the transport system, the method will combine them all into one agent. With normal conveyor belt (or comparable) transport systems there are these dependencies resulting in one agent for the complete transport system. This makes the coding of the control logic difficult and error-prone. Also the extension of such a transport system is normally difficult. The agentified plant is not extendable by default.

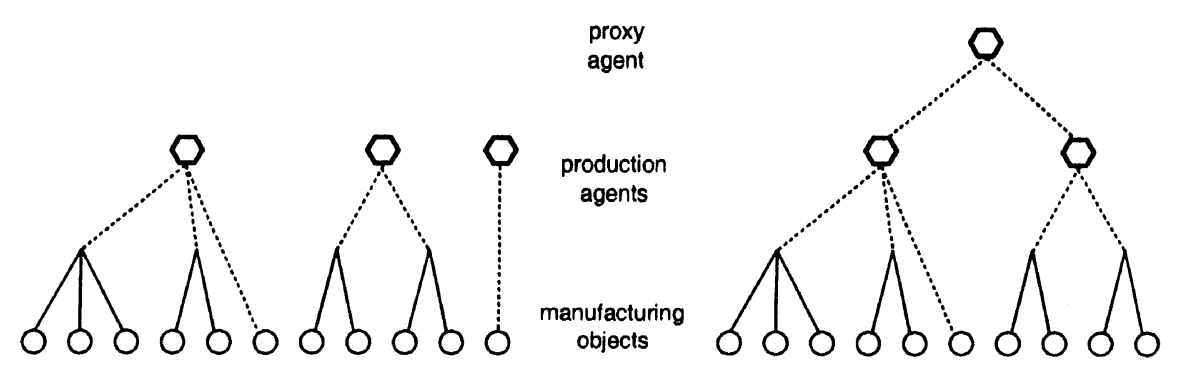

(a)

(b)

Figure 4- Flat versus hierarchical multi-agent system

In our case study this extension results in several transport agents. On top of these transport agents there is a facilitator. This facilitator is equivalent in functionality to the transport agent as identified in Figure 3.

\section{SOLUTIONS TO THE IDENTIFIED PROBLEMS}

To solve the problems identified in section 0 , we suggest to extend the method with a degree of dependency based on identified physical boundaries. In the aggregation steps the degree of dependency defines which objects will be aggregated directly and which objects will be aggregated in the form of proxy agents. The degree of dependency leads to a hierarchy of agents. The top level multi agent system of the plant consists of the same agents as identified by the IPA-method, but some of these agents may only be proxies for lower level multi-agent system. These proxy agents are in this case study facilitators (Shen, Norrie, 1997).

\section{CONCLUSION AND OUTLOOK}

This work proposes an approach that supports the design of agent-based manufacturing control systems for different industrial holonic manufacturing scenarios. The first phase of such approach is related to the "agentification" of the production scenario when considering the definition of a "physical / production agent". The results of the application of the approach to a pilot cell at industrial level are very promissory, showing that the approach seems to be very suited in 
accommodating heterogeneous hardware and software components in both their manufacturing control and information system, and in integrating existing/legacy systems. Further work will be oriented to the study of different existing industrial scenarios and to test the possibility for their "agentification", i.e., the method for agentification will be further improved. We expect to find also mediating proxy agents with this method, and to extend the agentification path to other production resources like of workpieces and work-plans.

\section{ACKNOWLEDGEMENTS}

We would like to express our thanks to the colleagues of the Fraunhofer Institute for Manufacturing Engineering and Automation, Stuttgart, Germany, for their support during the realisation of this work.

\section{REFERENCES}

1. Bohnenberger T, Fischer K, Gerber C. "Agents in Manufacturing: Online Scheduling and Production Plant Configuration”. In Proc. of $1^{\text {st }}$ Int. Symposium on Agent Systems and Applications, 1998.

2. Bussmann S, Schild K. "An Agent-Based Approach to the Control of Flexible Production Systems". In Proc. of the $8^{\text {th }}$ IEEE Conf. On Emerging Technologies and Factory Automation (ETFA'01), Sophia/Nice, France, 2001.

3. Bussmann S, Jennings NR, Wooldridge M. "On the identification of Agents in the Design of Production Control Systems". Agent-Oriented Software Engineering. Springer-Verlag, 2001.

4. Caselli S, Papaconstantinou C, Doty K, Navathe S. "A structure-function-control paradigm for knowledge-based modeling and design of manufacturing cells". Journal of Intelligent manufacturing, num. 3, pp. 11-30, 1992.

5. Christensen J. "Basic Principles of HMS Architecture". Proc. of the HMS'00 Int. Symposium, Kitakyushu, Japan, 2000.

6. Cornelio A, Navathe S. "Integration and cataloging of engineering design information". Proc. of the $1^{\text {st }}$ Int. Conf. on Systems Integration, IEEE Press, 1990.

7. Colombo AW, Neubert R, Schoop R. “A Solution to Holonic Control Systems". Proc. of the $8^{\text {th }}$ IEEE Conf. On Emerging Technologies and Factory Automation (ETFA'01), France, 2001.

8. Hayashi H. "The IMS International Collaborative Program". Proc. of the $24^{\text {th }}$ ISIR, Japan Industrial Robot Association. 1993.

9. Jennings NR, Wooldridge MJ. "Applications of Intelligent Agents". Agent Technology: Foundations, Applications, and Markets, pp. 3-28. 1998.

10. Parunak VD, Baker A, Clark S. "The AARIA Agent Architecture: From Manufacturing Requirements to Agent-Based System Design". Working Notes of the Agent-Based Manufacturing Workshop, Minneapolis, MN. 1998.

11. Ritter A, Baum W, Höpf M, Westkämper E. "Agentification for Production Systems". To appear in Proc ETAPS'02, Grenoble, France, April 2002.

12. Schoop R, Neubert R, Colombo AW. "A Multiagent-based Distributed Control Platform for Industrial Flexible Production Systems". Proc. of the IEEE IECON'2001, Denver, USA, 2001.

13. Shen W, Norrie D. "Facilitators, Mediators and Autonomous Agents". Proc. of the $2^{\text {nd }}$ Int. Workshop on CSCW in Design, Bangkok, Thailand, Nov. 1997, pp. 119-124.

14. Shen W, Norrie D. "Agent-Based Systems for Intelligent Manufacturing: A State-of-the-Art Survey". Int. Journal on Knowledge and Information Systems, 1(2), pp. 129-156. 1999.

15. Tharumarajah A, Wells AJ, Nemes L. "Comparison of the bionic, fractal and holonic manufacturing system concepts". Int. Journal Computer Integrated Manufacturing, vol. 9, num. 3, pp. 217-226.

16. Tzafestas S. "Modern Manufacturing Systems: An Information Technology Perspective". Advanced manufacturing Series - Computer-Assisted Management and Control of Manufacturing Systems. London. Springer Verlag. 1997.

17. http://www. fipa.org/docs/wps/f-wp-00009/f-wp-00009.html 